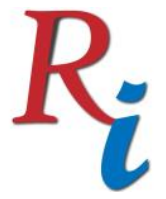

Asia Proceedings of Social Sciences

(APSS)

www.readersinsight.net/APSS

\title{
TESTING A FRAMEWORK FOR INDUSTRY 4.0 DIGITAL DISRUPTION-A STUDY IN MALAYSIAN SMES
}

\section{Sreenivasan Jayashree}

Associate Professor, Faculty of Management

Multimedia University

Persiaran Multimedia, 63100 Cyberjaya

Selangor, Malaysia

jayashree@mmu.edu.my

\author{
C. A. Malarvizhi
}

Senior Lecturer

Faculty of Management

Multimedia University, Persiaran Multimedia

63100 Cyberjaya, Selangor, Malaysia

malarvizhi@mmu.edu.my

\section{Mohammad Nurul Hassan Reza*}

PhD Researcher

Faculty of Management

Multimedia University, Persiaran Multimedia

63100 Cyberjaya, Selangor, Malaysia

hassanreza7171@gmail.com

*Corrosponding author's Email: hassanreza7171@gmail.com

Peer-review under responsibility of $5 t^{d}$ Asia International Conference 2019Scientific Committee

http://connectingasia.org/scientific-committee/

(c) 2019 Published by Readers Insight Publisher,

lat 306 Savoy Residencia, Block 3 F11/1,44000 Islamabad. Pakistan,

editor@readersinsight.net

This is an open access article under the CC BY-NC-ND license (http://creativecommons.org/licenses/by-nc-nd/4.0/). 


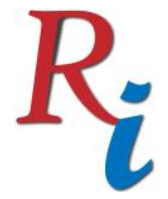

\section{Asia Proceedings of Social Sciences \\ (APSS) \\ www.readersinsight.net/APSS}

\section{A b s t r a c t}

Industry 4.0 has become a buzzword among the global industry and it is an amazing melting pot of disruptive technologies and is referred to as production-based industries digitalization transformation, driven by connected technologies. Malaysia is still ranging between industry 2.0 and 3.0 and unable to enter into the era of digital innovation whereas the neighboring countries are building bridges to connect to the era of Industry 4.0. The eleventh plan of Malaysia represents a crucial platform for the Malaysian SMEs to create the essential strategy relocation and this research integrates Industry 4.0 and sustainability addressing the thrust area of digital Malaysia to shift behavior from being consumption- to production-centric using digital technologies. Due to the lack of an integration model of 4.0 and environmental sustainability, the actual advantages are not recognized by SMEs and the purpose of this research will help to come up with a national policy/framework on Industry 4.0.

\section{Rese a r ch H igh I ight s}

SMEs are the backbone of the Malaysian economy (Kayadibi et al., 2013). Most of the SMEs are involved with business organizations and the contribution to GDP is nearly 47\% which can be increased to 50\% of production yield by 2020 (Thurasamyet al., 2009). Creating more jobs and deducting unemployment (SME Corp. Malaysia, 2012).

Malaysia is still ranging between industry 2.0 and 3.0 and cannot afford to enter into the era of digital innovation whereas a majority of the neighboring countries are building the bridge from Industry 3.0 to 4.0 . Therefore, it is the appropriate time to adopt the latest technologies of Industry 4.0 in the manufacturing sector especially in SMEs in Malaysia.

\section{Research Objectives}

The objectives of the study are as follows,

- To identify the dimensions of Industry 4.0 for the adoption of the latest technologies in the manufacturing sector.

- To investigate how the dimensions contribute to the effectiveness of industry 4.0.

- To examine the impact of Industry 4.0 on sustaniability. 


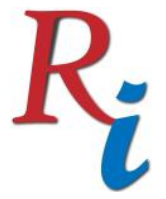

\section{Asia Proceedings of Social Sciences \\ (APSS) \\ www.readersinsight.net/APSS}

- To scrutinize how Industry 4.0 mediates the relationship between the dimensions of Industry 4.0 (independent variables, 1-4) and sustainability (dependent variable).

\section{Research Framework}

The research framework is as follows,

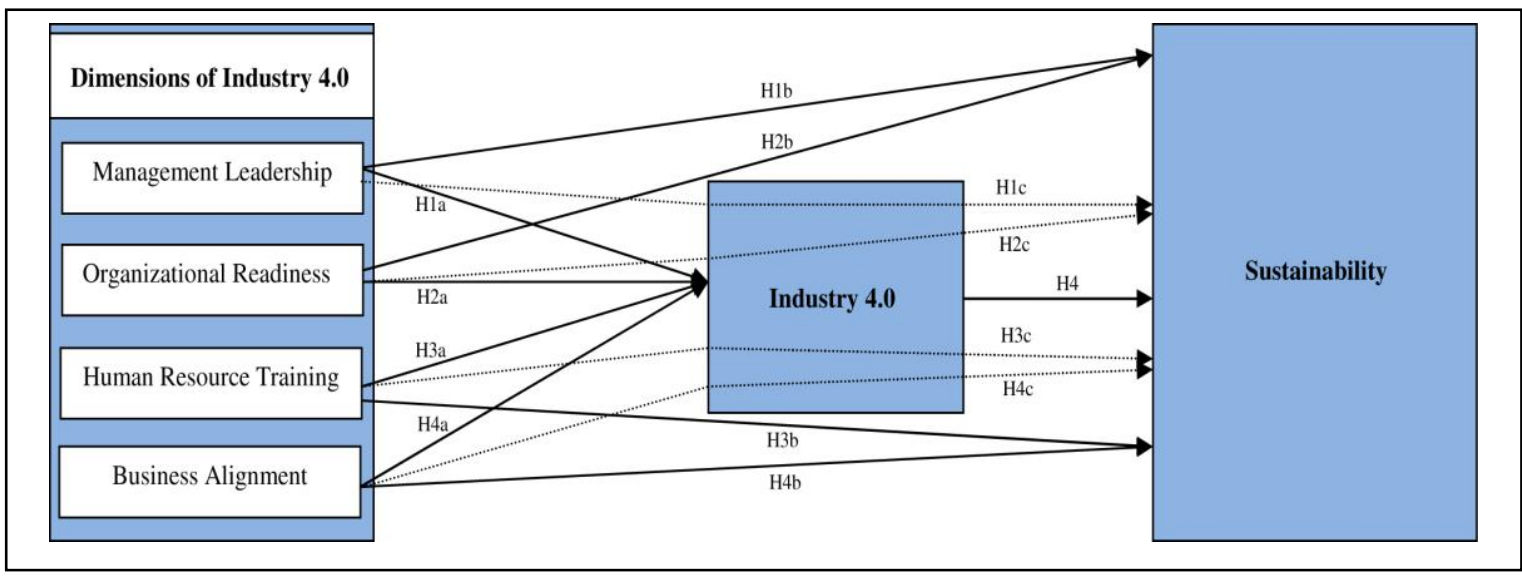

Fig. 1: Research Framework

According to the framework the dimensions of Industry 4.0 i.e. Management Leadership, Organizational Readiness, Human Resource Training and Business Alignment are the independent variables. Industry 4.0 is the mediating variable and Sustainability is the dependent variable. Industry 4.0 mediates the relationship between the independent variables and the dependent variable.

\section{Methodology}

A novel model and its impact on organizational sustainability is proposed for the SMEs of Malaysia based on the Eleventh Master Plan of Malaysia. The cross-sectional survey will be conducted from Malaysian SMEs. Malaysian SMEs are the target population and the samples will be selected from SME Corporation. The survey will be carried out in Selangor, Johor Bahru, Melaka and Kuala Lumpur. The study will use Structural Equation Modeling (SEM) and will obtain the necessary information through a questionnaire-based survey. 


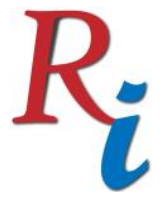

Asia Proceedings of Social Sciences

(APSS)

www.readersinsight.net/APSS

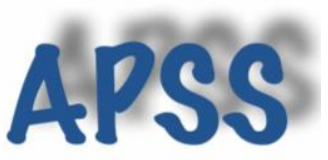

\section{Literature Review}

Management Leadership: Management leadership is very important in achieving sustainability and the leadership style has a significant impact on the implementation of the latest technologies in manufacturing companies (Shao, Feng, \& Hu, 2017). Industry 4.0 requires a transformational leadership style for encouraging employees to ignore their personal interest in attaining the goal of the organization (Politis, 2001).

Organizational Readiness for change: Readiness for change of an organization can forecast the attainment of change management procedures (R. A. Jones, Jimmieson, \& Griffiths, 2005), and Industry 4.0 technologies will influence the work processes in the production system.

Human Resource Training: Recognizing, managing and executing the new tasks due to the acceptance of Industry 4.0 technologies involve suitable training and skill development for the workforce (Waibel, Steenkamp, Moloko, \& Oosthuizen, 2017).

Business Alignment: Business alignment involves the change of technological potential into improving organizational results (Bergeron, Raymond, \& Rivard, 2004). Most of the time, the implementation of new technologies flops because of an absence of the alignment between technological and organizational intentions (Henderson \& Venkatraman, 1999) and organizations cannot attain success without an entire alignment with information technology (Avison, Jones, Powell, \& Wilson, 2004).

\section{Findings}

The findings of the paper may help organizations to identify the dimensions of Industry 4.0 that will help them to take appropriate initiatives for the adoption of the latest technologies to build competitive advantage and the economy as well.

\section{Acknowledgment}

We would like to thank the Ministry of Higher Education, Malaysia for giving us the opportunity to carry out this project under the FRGS grant. 


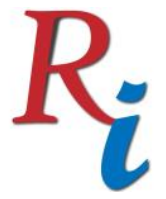

Asia Proceedings of Social Sciences

(APSS)

www.readersinsight.net/APSS

\section{References}

Avison, D., Jones, J., Powell, P., \& Wilson, D. (2004). Using and Validating the Strategic Alignment Model. Journal of Strategic Information Systems, 13, 223-246.

Henderson, J. C., \& Venkatraman, N. (1999). Strategic Alignment: Leveraging Information Technology for Transforming Organizations. IBM Systems Journal, 32(1), 472-484.

Jones, R. A., Jimmieson, N. L., \& Griffiths, A. (2005). The Impact of Organizational Culture and Reshaping Capabilities on Change Implementation Success: The Mediating Role of Readiness for Change. Journal of Management Studies, 42(2).

Kayadibi, S., Polat, R. and Fidan, Y. (2013). Small and medium-sized business in Malaysian economy: Case of Turkish entrepreneurs in Kuala Lumpur. Business Economy, 31, pp.265-281.

Politis, J. D. (2001). The Relationship of Various Leadership Styles to Knowledge Management. Leadership \& Organization Development Journal, 22(8), 354-364.

Shao, Z., Feng, Y., \& Hu, Q. (2017). Impact of Top Management Leadership Styles on ERP Assimilation and the Role of Organizational Learning. Information \& Management, 54, 902-919.

SME Corp, (2012). Summary SME Masterplan 2012-2020, Kuala Lumpur: Small and Medium Enterprise Corporation Malaysia. SME Corp., Malaysia.

Thurasamy, R., Mohamad, O., Omar, A. and Marimuthu, M. (2009). Technology adoption among small and medium enterprises (SME's): A research agenda. World Academy of Science, Engineering and Technology, 53, pp.943-946.

Waibel, M. W., Steenkamp, L. P., Moloko, N., \& Oosthuizen, G. A. (2017). Investigating the Effects of Smart Production Systems on Sustainability Elements. Procedia Manufacturing, 8, 731-737. 


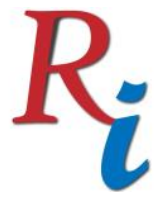

Author's Biography

\section{Asia Proceedings of Social Sciences}

(APSS)

www.readersinsight.net/APSS

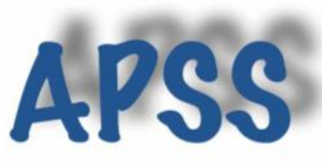

Dr Sreenivasan Jayashree, Associate Professor, Multimedia University, Cyberjaya, Malaysia has widely published in many international journals and has secured many grants. She has supervised many students. Her areas of interest are environmental management, strategic management, Industry 4.0, waste management, consumer studies.

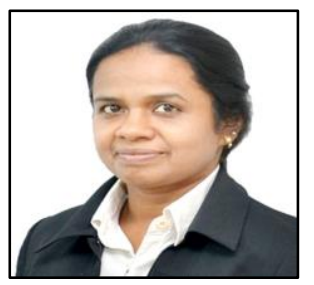

Dr. C. A. Malarvizhi, Senior Lecturer, Multimedia University, Cyberjaya, Malaysia has more than 18 years of teaching and research experience in Economics, Environment and Health issues, Knowledge Management and Tourism Development. She regularly publishes in journals and presents at international conferences. She has guided many PhD research scholars, Master students, and undergraduate students.

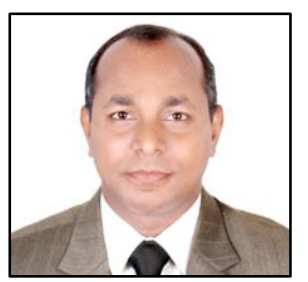

Mohammad Nurul Hassan Reza, PhD Researcher, Faculty of Management, Multimedia University, Cyberjaya, Malaysia. Graduate Research Assistant of the project titled 'Testing a Framework for Industry 4.0 Digital Disruption-A Crunch Point for Environmental Sustainability in Malaysian SMEs', MoE, Malaysia. Couples of theoretical and conceptual articles have been published in Scopus indexed journals and some articles are accepted for publication. 